\title{
Kimura disease accompanied with Nephrotic syndrome in a 45-year-old male
}

\author{
Yu Gong ${ }^{1 \dagger}$, Jun-Ying $\mathrm{Gu}^{1 \dagger}$, Sony Labh ${ }^{2}$ and Yu-Ling Shi ${ }^{{ }^{*}}$
}

\begin{abstract}
Kimura disease (KD) is an uncommon chronic inflammatory disorder of unknown etiology, occurs mainly in Asian young males, presenting as subcutaneous growing masses, with a predilection for head and neck, with or without satellite lymphadenopathy. Herein, we report a case of an atypical manifestation of KD accompanied with NS in a middle-aged man, though the patient was clinically misdiagnosed previously. The diagnosis of KD can be difficult and misleading, so we must explore the main points of KD so as to prevent misdiagnosis.
\end{abstract}

Keywords: Kimura disease, Nephrotic syndrome, Angiolymphoid hyperplasia with eosinophilia, Prednisone

\section{Letter to the editor}

$\mathrm{KD}$ is an uncommon chronic inflammatory disorder of unknown cause, involving subcutaneous tissue, predominantly in the head and neck region. It can be associated with lymphadenopathy (both local and distant), obvious peripheral blood eosinophilia, and an elevated IgE level [1]. Most cases reported to date involve young Asian males, with most patients being aged between 20 and 40 years [2]. The incidence of $\mathrm{KD}$ with coexisting renal disease ranges from $10 \%$ to $60 \%[3,4]$. Herein, we report an atypical manifestation of KD accompanied with nephrotic syndrome (NS) occurring in a 45-year-old man.

A 45-year-old Chinese man came to our department with a soft mass in medial aspect of his right upper arm. According to the patient, the mass appeared in 2003 for the first time and that was without any obvious cause. He became aware of the mass after about 5 years when he noticed that the enlargement was gradually progressive. Then he visited general surgery department in October 2008 and underwent surgical resection of mass after 3 months in January 2009.

The histopathology report of the mass at that time revealed a proliferation of lymphoid follicles and diffuse infiltration of eosinophil, and WBC: 8200/dL (eosinophil: $38 \%)$. So it was diagnosed provisionally as a suspected case of parasitic infection by a physician, and then the patient wasn't followed up.

In 2013, the lesion reappeared and gradually became larger than before, so he visited our clinic. Physical examination revealed a firm, nontender, mobile, subcutaneous mass of $4 \mathrm{~cm} \times 5 \mathrm{~cm}$ (Figure 1). The overlying skin was normal except for a $5 \mathrm{~cm}$ long scar (Figure 1). The patient's blood pressure was 135/90 $\mathrm{mmHg}$. The laboratory values were as follows: creatinine $(2.4 \mathrm{mg} / \mathrm{dL})$, normal electrolytes, low serum albumin $(28 \mathrm{~g} / \mathrm{L})$, hypertriglyceridemia $(3.2 \mathrm{mmol} / \mathrm{L})$, proteinuria $(3.5 \mathrm{~g} / \mathrm{d})$, WBC (8360/dL), eosinophilia (42\% ), haemoglobin (13.6 g/dL), $\operatorname{IgE}(17100 \mathrm{IU} / \mathrm{ml})$. Antinuclear antibody and other disease specific autoantibodies were negative. The bilateral lymph nodes (LN) of neck and axillae were enlarged. Investigations for a haematological malignancy including immunophenotyping of circulating lymphocytes, search for clonal $T$ cell population and FIP1L1-PDGFRA fusion gene mutation, and examination of a bone marrow biopsy all gave negative results.

Histological examination of a biopsy sample showed a proliferation of lymphoid follicles with distinct germinal centres (Figure 2a), capillary proliferation (Figure 2b), and diffuse infiltration of eosinophil and eosinophilic microabscess (Figure $2 \mathrm{c}$ and $\mathrm{d}$ ).

\footnotetext{
*Correspondence: shiyuling1973@gmail.com

${ }^{\dagger}$ Equal contributors

'Department of Dermatology, Shanghai Tenth People's Hospital, Tongji

University School of Medicine, 301, Middle Yanchang Rd, Shanghai 200072,

China

Full list of author information is available at the end of the article
}

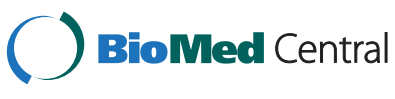

(c) 2015 Gong et al.; licensee BioMed Central. This is an Open Access article distributed under the terms of the Creative Commons Attribution License (http://creativecommons.org/licenses/by/4.0), which permits unrestricted use, distribution, and reproduction in any medium, provided the original work is properly credited. The Creative Commons Public Domain Dedication waiver (http://creativecommons.org/publicdomain/zero/1.0/) applies to the data made available in this article, unless otherwise stated. 


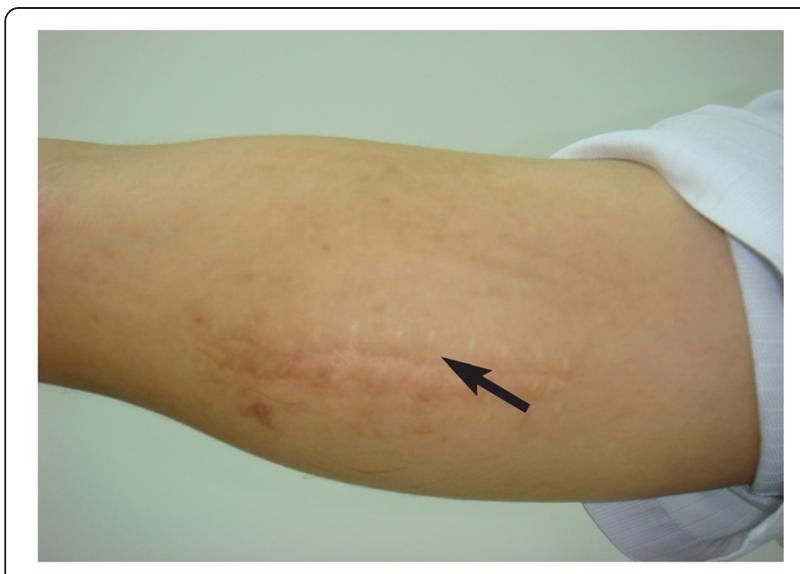

Figure 1 Clinical appearance of the case: a nontender firm subcutaneous swelling of $4 \mathrm{~cm} \times 5 \mathrm{~cm}$ in size in the right upper arm region (arrow).

The final diagnosis was KD accompanied with NS. But the patient refused the renal biopsy. After integrity surgical excision of the mass, he was treated with oral prednisone $30 \mathrm{mg}$ per day for 4 months and responded well with normalization of eosinophil counts and $\operatorname{IgE}$ values, disappearance of proteinuria after 3 months. In addition, the enlarged LN shrunk to normal after 4 months. Currently, the patient is only on a low dose of oral prednisone $(7.5 \mathrm{mg} / \mathrm{d})$. There has been no recurrence of the disease for 1 year.
Association of KD with renal disease in the form of proteinuria and NS is well recognized. Proteinuria may occur in $12-16 \%$ of patients and $59-78 \%$ of them have a NS $[3,4]$. The renal pathologies reported in China have included minimal change disease, mesangioproliferative and membranous nephropathy, while a wider spectrum of histological lesions have been reported in other countries [5]. In our case, the patient refused the renal biopsy, so we didn't know renal pathology.

$\mathrm{KD}$ is often confused with malignancies, $\mathrm{T}$ cell lymphoma, Hodgkin's disease, parasitic infection and histiocytosis $\mathrm{X}$. Ultrasound, CT, and magnetic resonance imaging (MRI) might be diagnostic and can help staging the extent and progression of the disease as well as the lymph node involvement. The peripheral blood eosinophilia can also mimic a parasitic infection or an allergic reaction. However, the lesion that bears the closest resemblance to $\mathrm{KD}$ is Angiolymphoid Hyperplasia with Eosinophilia (ALHE). The clinical and histological features of KD and ALHE are compared in Table $1[6,7]$.

Treatment for KD includes surgical resection and regional or systemic steroid therapy [8]. Cytotoxic therapy and irradiation have also been utilized. Surgical excision of the lesion(s) is the first line therapy but relapses are frequent [5]. Systemic corticotherapy with prednisone is prescribed when renal involvement is present, but with a risk of relapse on a
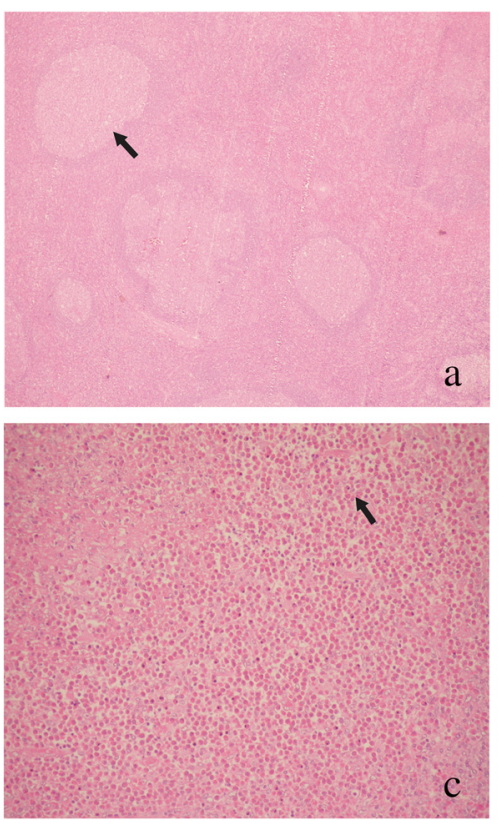

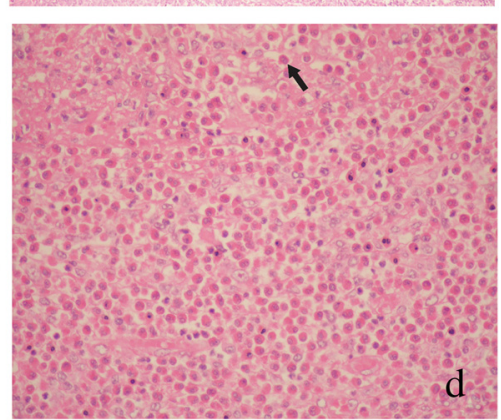

Figure 2 Histologic examination of a biopsy sample from the subcutaneous mass of the upper arm ( $\mathrm{H}$ and $\mathrm{E})$ : (a) proliferation of lymphoid follicles with distinct germinal centres (arrow; $\times 40$ ); (b) vascular proliferation (arrow; $\times 100$ ); (c, d) formation of eosinophilic microabscess and intense eosinophilic infiltration (arrow; $c \times 200 ; d \times 400$ ). 
Table 1 A comparison of the clinical and histological features of KD with ALHE

\begin{tabular}{|c|c|c|}
\hline & Kimura disease & Angiolymphoid hyperplasia with eosinophilia \\
\hline \multicolumn{3}{|l|}{ clinical features } \\
\hline Sex & Female predominance (70\%) & Male predominance (85\%) \\
\hline Age & Young adulthood & Young to middle age \\
\hline Race & More common in Asians & Occurs in all races \\
\hline Location & Head and neck & Head and neck \\
\hline Presentation & Localized subcutaneous mass & Dermal papules or nodules \\
\hline Number & Single or multiple & Usually multiple \\
\hline Size & Average $3 \mathrm{~cm}$ & Average $1 \mathrm{~cm}$ \\
\hline Lymph node involvement & Common & Rare \\
\hline peripheral eosinophilia & Almost invariably present & Rare (20\%) \\
\hline $\begin{array}{l}\text { Serum immunoglobulin } \\
\text { E (lgE) level }\end{array}$ & Elevated & Normal \\
\hline Renal involvement & Occasional (21\%) & Rare \\
\hline Recurrence rate & $30 \%$ & $15-40 \%$ \\
\hline \multicolumn{3}{|l|}{ Histopathological features } \\
\hline Depth & Subcutaneous, muscle & Cutaneous, subcutaneous \\
\hline Vascular proliferation & $\begin{array}{l}\text { Some degree of vascular } \\
\text { proliferation }\end{array}$ & Florid vascular proliferation \\
\hline Lymphoid follicles & Always found & May be present \\
\hline Eosinophils & Abundant & Sparse to abundant \\
\hline Eosinophils abscesses & Present & Not seen \\
\hline Endothelium & Flattened & Cuboidal to dome shaped:"Histiocytoid" \\
\hline Fibrosis & Present & Absent \\
\hline
\end{tabular}

withdrawal of medicine. In our case, our patient who is a middle-aged man presented with atypical KD with renal involvement that responded well to prednisone without relapse. The treatment resulted in rapid remission of NS along with the normalization of eosinophil count and IgE levels. The dose of prednisone had been tapered to $7.5 \mathrm{mg} / \mathrm{d}$ for 7 months and disease had not relapsed. He is still being followed-up.

\section{Consent}

Written informed consent was obtained from the patient for the publication of this report and any accompanying images.

\section{Competing interests}

The authors declare that they have no competing interests.

\section{Authors' contributions}

Jun-Ying Gu, Yu Gong and Yu-Ling Shi participated in conception of the idea, Yu Gong and Jun-Ying Gu have been involved in drafting the manuscript. Yu Gong and Sony Labh has been involved in revising it critically for important intellectual content. All authors performed the pathological and immunohistochemical interpretation of the tumor tissue. All authors have read and approved the final manuscript.

\section{Acknowledgement}

All the authors of this article and the patient in the text.

\section{Source(s) of support}

This work was supported in parts by grants from the Science and

Technology Commission of Shanghai Municipality Grant (134119b0700).

\section{Author details}

${ }^{1}$ Department of Dermatology, Shanghai Tenth People's Hospital, Tongji University School of Medicine, 301, Middle Yanchang Rd, Shanghai 200072, China. ${ }^{2}$ Department of Dermatology, Tongji University School of Medicine, Shanghai, China.

Received: 31 October 2014 Accepted: 16 April 2015

Published online: 28 April 2015

\section{References}

1. Messina MTD, Armstrong WB, Pena F, Allison G, Kim JKV. Kimura's disease: two case reports and a literature review. Annals of Otology, Rhinology and Laryngology. 1998;107(12):1066-71.

2. Sorbello M, Laudini A, Morello G, Sidoti MT, Maugeri JG, Giaquinta A, et al. Anaesthesiological implications of Kimura's disease: a case report. J Med Case Rep. 2009;3:7316.

3. Park SW, Kim HJ, Sung KJ, Lee JH, Park IS. Kimura disease: CT and MR imaging findings. AJNR Am J Neuroradiol. 2012;33(4):784-8.

4. Fouda MA, Gheith O, Refaie A, El-Saeed M, Bakr A, Wafa E, et al. Kimura Disease: $A$ case report and review of the literature with a new management protocol. Int J Nephrol. 2010;2011:673908.

5. Liu C, Hu W, Chen H, Tang Z, Zeng C, Liu Z, et al. Clinical and pathological study of Kimura's disease with renal involvement. J Nephrol. 2008;21:517-25. 
6. Dik VK, van der Wiel BA, Vasmel WL. Kimura's disease of the parotid glands and multiple cervical lymph nodes. Neth J Med. 2010;68:175-7.

7. Sah P, Kamath A, Aramanadka C, Radhakrishnan R. Kimura's disease - An unusual presentation involving subcutaneous tissue, parotid gland and lymph node. J Oral Maxillofac Pathol. 2013;17(3):455-9.

8. Tseng CF, Lin HC, Huang SC, Su CY. Kimura's disease presenting as bilateral parotid masses. Eur Arch Otorhinolaryngol. 2005;262(1):8-10.

Submit your next manuscript to BioMed Central and take full advantage of:

- Convenient online submission

- Thorough peer review

- No space constraints or color figure charges

- Immediate publication on acceptance

- Inclusion in PubMed, CAS, Scopus and Google Scholar

- Research which is freely available for redistribution 